\title{
Percutaneous Transcatheter Closure of Ruptured Sinus of Valsalva Aneurysm: Immediate Result and Long-Term Follow-Up
}

\author{
Sudhir Chandra Sinha, MD, DM, FACC, FSCAI ${ }^{1}$ Vipperla Sujatha, MD, DM, FIC, FSCAI ${ }^{1}$ \\ Anil Kumar Mahapatro, MD, DM ${ }^{1}$ \\ ${ }^{1}$ Department of Cardiology, Indus Hospitals, Visakhapatnam, India \\ Address for correspondence Sudhir Chandra Sinha, MD, DM, FACC, \\ FSCAI, Department of Cardiology, Indus Hospitals, KGH Down Road, \\ Int J Angiol 2015;24:99-104. \\ Maharanipeta, Visakhapatnam, India 530002 \\ (e-mail: scsinha_cardio@yahoo.com).
}

\begin{abstract}
There is scarcity of data on closure and long-term follow-up of percutaneous treatment of ruptured sinus of Valsalva aneurysm (RSOVA). In this article, we present our experience in percutaneous closure of this defect. Between December 2009 and July 2014, 11 cases of RSOVA were referred to our hospital. Eight of the 11 cases (72.7\%) were considered for percutaneous closure. Seven of the eight (87.5\%) patients underwent successful percutaneous closure. There were four females and three males in the age group of 16 to 48 years (mean $24.7 \pm 6.1$ years). Associated defects were bicuspid aortic valve in one patient, mild preexisting aortic regurgitation in two patients, and healed infective endocarditis in one patient. Echocardiography revealed RSOVA from right coronary sinus (RCS) to right atrium (RA) in one patient (14.3\%), RCS to right ventricular outflow in three patients (42.8\%), and noncoronary sinus ruptured

Keywords

- aneurysm

- cardiac catheterization

- cardiac device

- endocarditis

- endovascular procedure

- percutaneous

- cardiac surgery into RA in three patients (42.8\%). All patients were symptomatic in New York Heart Association (NYHA) class II to IV. The defect size ranged from 7 to $10 \mathrm{~mm}$ (mean $8.4 \pm 1.3 \mathrm{~mm}$ ). The defects were closed from the venous side with device selection 2 to $4 \mathrm{~mm}$ higher than the defect size under fluoroscopy and transesophageal echocardiography guidance. Technical success was $87.5 \%$. The mean device size was $12.0 \pm 1.6$ $\mathrm{mm} / 10.0 \pm 1.6 \mathrm{~mm}$. Six out of seven patients (85.7\%) had complete disappearance of shunt before discharge. During 1 to 55 months follow-up, all patients were in NYHA class I. There was no residual shunt, progression of AR or new AR, infective endocarditis or device embolization. Percutaneous closure of RSOVA appears to be a safe alternative to surgical therapy, with high technical success and excellent long-term outcome.
\end{abstract}

Sinus of Valsalva aneurysm is an uncommon congenital heart defect (CHD) accounting for $<1 \%$ of all CHDs. ${ }^{1}$ The typical aneurysm is a blind pouch projecting from one of the sinuses into the right atrium or right ventricle. Aneurysms form due to congenital weakness at the junction of the aortic media and annulus fibrosus. ${ }^{2}$ Unruptured aneurysms account for almost $20 \%$ cases. $^{3}$ Aneurysms more commonly involve right coronary sinus (RCS) (70\%), noncoronary sinus (29\%), and rarely involve left coronary sinus (1\%). ${ }^{4}$ Aneurysms of RCS may rupture into the right ventricle or right atrium, whereas aneurysms of noncoronary sinus (NCS) rupture into the right atrium. Rarely, aneurysms may rupture into the pulmonary artery, left ventricle, left atrium, or pericardial cavity. ${ }^{5}$ Ruptured sinus of Valsalva aneurysms (RSOVAs) are more common in males than females (male:female, 4:1). The average age of rupture is 34 years, with a range of 11 to 67 years. published online January 14, 2015
Copyright $\odot 2015$ by Thieme Medical Publishers, Inc., 333 Seventh Avenue, New York, NY 10001, USA. Tel: +1(212) 584-4662.
DOI http://dx.doi.org/ 10.1055/s-0034-1396948. ISSN 1061-1711. 
Rupture usually manifests as a sudden onset of chest pain and acute heart failure in most of the cases. Death usually occurs within 1 year of untreated RSOVA. ${ }^{5}$ Surgery remains a mainstay treatment for RSOVA. Percutaneous treatment is emerging. Due to the relative rarity of this condition, larger data on percutaneous treatment of RSOVA is lacking. Most of the publications on percutaneous treatment are in the form of case reports. We report our experience in percutaneous closure of RSOVA with special attention to case selection and long-term outcomes.

\section{Materials and Methods}

Between December 2009 and July 2014, 11 patients diagnosed with RSOVA were referred for management. All these patients were first stabilized with medical management for congestive cardiac failure. Cardiac catheterization, coronary and aortic root angiogram were performed before nonsurgical or surgical intervention. All cases were discussed with the cardiac surgery team after completion of angiogram. All patients were given a choice between surgical and percutaneous treatment. Percutaneous intervention was performed in the second sitting after obtaining a written informed consent for the procedure.

The procedure was performed under local anesthesia with transesophageal echocardiography (TEE) guidance. All patients were treated with Clopidogrel (Intas Pharmaceuticals Ltd, Ahmedabad, India) $300 \mathrm{mg}$ and dispersible Aspirin (Reckitt Benckiser, UK) 350 mg loading before the procedure. Both the femoral vein and femoral artery were accessed with $6 \mathrm{~F}$ sheath. All the patients received intravenous heparin 100 $\mathrm{IU} / \mathrm{kg}$ after femoral access. Aortic root angiography was repeated in the left anterior oblique (LAO) and right anterior oblique (RAO) views to better delineate the anatomy. The left anterior oblique projection was preferred for RSOVA draining into the right atrium (RA) and the right anterior oblique view for RSOVA into right ventricular outflow tract (RVOT). Size of RSOVA was measured at its aortic end both on the TEE and angiography. Relationship to the nearby aortic cusp and coronary artery, and the possible impact of the device on aortic valve morphology was assessed with TEE. The larger of the two measurements was considered for device selection. The size of Cocoon Duct Occluder (CDO) (Vascular Innovations, Nonthaburi, Thailand) selected was such that its aortic segment was 2 to $4 \mathrm{~mm}$ larger than the defect size based on visual clue. The defect was crossed from the aortic side using a 6F Judkins right coronary catheter and a $0.035 \mathrm{in} .300 \mathrm{~cm}$ J-tip Terumo wire (Terumo Medical Corporation, Somerset, NJ). It was then snared with a $10 \mathrm{~mm}$ Amplatz gooseneck snare (AGA Medical Corporation, Plymouth, MN) from the superior or inferior vena cava or the pulmonary artery and exteriorized out of the femoral vein. A stable arteriovenous wire loop was thus established, over which the delivery sheath compatible with the selected device size was introduced from the femoral vein and placed into the ascending aorta across the defect. An appropriately sized CDO with its attached delivery cable was then inserted through the delivery sheath and its aortic disc was deployed in the ascending aorta. The whole assembly was pulled back till the aortic disc blocked the aortic end of the RSOVA, as seen on online TEE and aortic root angiogram. After confirming the precise placement, the rest of the device was deployed on the right side across the defect. During this maneuver, special care was taken to ensure seating of the aortic disc on the aortic side without slippage into the aneurysm. Tension on the delivery cable was minimized to avoid slippage of the device. The device was then released from the delivery cable only after making certain that there was no significant aortic regurgitation (AR) or any encroachment on coronary arteries as seen on TEE and angiography (-Fig. 1). All patients were discharged 48 to 72 hours after the procedure. All patients received Clopidogrel $75 \mathrm{mg}$ and Aspirin $150 \mathrm{mg}$ daily for 6 months after the procedure. They were followed clinically and by transthoracic echocardiogram at discharge: 1 month, 3 months, and every 6 months thereafter till date. Procedure-related AR was defined as the occurrence of any grade of new AR or worsening by more than one grade of preexisting AR.

\section{Results}

The patient characteristics are summarized in - Table 1. There were seven males (66.6\%) and four females (33.3\%); the male: female ratio is $1.75: 1$. The mean age in the percutaneous group was $24.7 \pm 6.1$ years (median, 24 years). The associated defects were bicuspid aortic valve in one patient, mild preexisting AR in two patients, and healed infective endocarditis (IE) in one patient. All patients were in New York Heart Association (NYHA) class II to IV at presentation. All patients received adequate medical management before cardiac catheterization and percutaneous closure. Percutaneous closure was attempted in eight patients (72.7\%). Seven of the eight patients underwent successful closure (technical success 87.5\%). Patient number 4 was also taken up for percutaneous closure, but a 16/14 CDO slipped and hence the procedure was abandoned. Seven of the 11 patients (66.6\%) had defects communicating between right coronary cusp (RCC) and RVOT, one patient (9.1\%) had defect communicating between RCC and RA, and three patients (27.3\%) had defect communicating between noncoronary cusp (NCC) and RA. Mean defect size was $10.00 \pm 2.72 \mathrm{~mm}$ overall and $8.28 \pm 1.49 \mathrm{~mm}$ (range $7-10 \mathrm{~mm}$ ) in percutaneous intervention group. The mean device size was $12.0 \pm 1.6 \mathrm{~mm} /$ $10.0 \pm 1.6 \mathrm{~mm}$. Six of the seven patients $(85.7 \%)$ had complete disappearance of shunt at 24 hours and all patients had complete disappearance of shunt at 1 month follow-up. One of the 11 patients had previously treated IE and there were no worsening or new features of IE during 46 months follow-up. Mild AR was present at the baseline in four of the seven intervention patients (57.1\%). There was no new AR or worsening of AR. One of the 11 patients was a 3-month postpartum female with RSOVA, possibly an acquired RSOVA. All patients were in sinus rhythm or in sinus tachycardia at the time of the procedure. Mean ratio of pulmonary to systemic flow (Qp/Qs) was 2.75:1. Mean follow-up time in intervention patients was $28.14 \pm 21.49$ months (range, 1-55 months; median, 34 months). There was no death or need for any subsequent surgery. All patients improved to NYHA class I. Oral antiplatelets were continued for 6 months in all patients. 
Table 1 Clinical and procedural data

\begin{tabular}{|c|c|c|c|c|c|c|c|c|c|c|c|}
\hline S.No. & Age & Gender & $\begin{array}{l}\text { NYHHA } \\
\text { class }\end{array}$ & $\begin{array}{l}\text { Defect } \\
\text { location }\end{array}$ & $\begin{array}{l}\text { Defect } \\
\text { size } \\
(\mathrm{mm})\end{array}$ & $\begin{array}{l}\text { Associated } \\
\text { problems }\end{array}$ & $\begin{array}{l}\text { Device } \\
\text { size }\end{array}$ & $\begin{array}{l}\text { Immediate } \\
\text { result }\end{array}$ & $\begin{array}{l}\text { Follow- } \\
\text { up } \\
(\mathrm{m})\end{array}$ & $\begin{array}{l}\text { Residual } \\
\text { shunt }\end{array}$ & $\begin{array}{l}\text { NYHA } \\
\text { class }\end{array}$ \\
\hline 1 & 25 & $\mathrm{~F}$ & III & RCC-RVOT & 7 & None & $10 / 8$ & $\begin{array}{l}\text { Mild } \\
\text { shunt }\end{array}$ & 55 & None & 1 \\
\hline 2 & 21 & $M$ & III & NCC-RA & 6 & $\begin{array}{l}\text { Healed } \\
\text { IE, } \\
\text { mild AR }\end{array}$ & $10 / 8$ & $\begin{array}{l}\text { No } \\
\text { shunt }\end{array}$ & 46 & None & 1 \\
\hline 3 & 16 & $\mathrm{~F}$ & IV & RCC-RVOT & 8 & Mild AR & $12 / 10$ & $\begin{array}{l}\text { No } \\
\text { Shunt }\end{array}$ & 43 & None & I \\
\hline $4^{a}$ & 41 & $M$ & IV & RCC-RVOT & 12 & None & Surgical & $\begin{array}{l}\text { No } \\
\text { shunt }\end{array}$ & 41 & None & 1 \\
\hline 5 & 34 & $M$ & III & NCC-RA & 8 & Mild AR & $12 / 10$ & $\begin{array}{l}\text { No } \\
\text { Shunt }\end{array}$ & 34 & None & 1 \\
\hline 6 & 34 & $M$ & III & RCC-RVOT & 14 & $\begin{array}{l}\text { Severe } \\
\text { TR, } \\
\text { RVD }\end{array}$ & Surgical & $\begin{array}{l}\text { No } \\
\text { shunt }\end{array}$ & 19 & None & 1 \\
\hline 7 & 51 & $M$ & IV & RCC-RVOT & 14 & VSD & Surgical & $\begin{array}{l}\text { No } \\
\text { Shunt }\end{array}$ & 12 & None & 1 \\
\hline 8 & 28 & $M$ & IV & RCC-RA & 9 & None & $12 / 10$ & No Shunt & 11 & None & 1 \\
\hline 9 & 65 & $\mathrm{M}$ & IV & RCC-RVOT & 12 & $\begin{array}{l}\text { CAD, } \\
\text { LVD }\end{array}$ & Surgical & No Shunt & 8 & None & I \\
\hline 10 & 24 & $\mathrm{~F}$ & III & NCC-RA & 10 & $\begin{array}{l}\text { Postpartum, } \\
\text { mild AR }\end{array}$ & $14 / 12$ & No shunt & 7 & None & 1 \\
\hline 11 & 48 & $\mathrm{~F}$ & IV & RCC-RVOT & 10 & None & $14 / 12$ & No shunt & 1 & None & I \\
\hline
\end{tabular}

Abbreviations: AR, aortic regurgitation; CAD, coronary artery disease; F, female; IE, infective endocarditis; LVD, left ventricular dysfunction; M, male; NCC, noncoronary cusp; NYHA, New York Heart Association; RA, right atrium; RCC, right coronary cusp; RVD, right ventricular dysfunction; RVOT, right ventricular outflow tract; TR, tricuspid regurgitation; VSD, ventricular septal defect.

a Device closure failed in this patient.

\section{Discussion}

Aneurysms of sinus of Valsalva are rare, and, hence, the experience remains limited. Surgery has been the gold standard treatment for RSOVA. However, the morphological features of RSOVA make it amenable to percutaneous closure. The procedure used for closure is practically the same as in the ventricular septal defect (VSD) closure. We routinely used TEE in RSOVA closure. Though initial reports indicated use of sizing balloon, ${ }^{6}$ currently it is not needed. Crossing the defect is much easier than VSD, but positioning needs patience, especially in cases of aneurysms leading to RVOT, where sometimes angiographic views appear suboptimal. Also, the aortic end of the device should be deployed into the aorta and not into the "windsock." Since the first report of device closure of RSOVA in $1994,{ }^{7}$ various case reports have been published using patent ductus arteriosus (PDA) occluders, VSD occluders, atrial septal defect (ASD) occluders, Gianturco coils, Rashkind umbrella, etc. (-Table 2). However, PDA occluders are currently favored.

Angiographic identification of cusps is vital to the closure procedure. Unless the anatomy is clearly defined on angiography, one should not proceed for device closure, as there is a good chance of failure or complications. In anteroposterior projection, the posterior or NCC and right cusps lie along the lateral borders of the aorta, with the NCC lower than the RCC. In LAO or lateral projection, the right and left cusps form the borders, with the LCC lower than the RCC. In RAO projection, the RCC lies on the left and is related to the RVOT, whereas the NCC forms the right border of the aorta - Fig. 2. $^{8}$

We attempted percutaneous closure initially in all cases enthused by initial successes. However, in case 4, we failed to deploy even the 16/14 device and, hence, referred for surgical correction. This made us understand the limitations of such a procedure. We resisted going for a higher device, as we felt it might lead to AR. Defects larger than $10 \mathrm{~mm}$ were closed by Guan et al using 14 to $18 \mathrm{~mm}$ PDA device. 9,10 $^{9}$

We chose CDO (-Fig. 3 ) because of our familiarity with this device and price concerns. The device is practically similar to Amplatz duct Occluder (ADO; St Jude Medical, Saint Paul, MN). As per the manufacturer's specifications, this device is made of nano-platinum coating which provides superior biocompatible properties compared with bare nitinol. This coating prevents Nickel leaching into the bloodstream. It also prevents corrosion of Nitinol wire frame in long-term implants. Presence of Platinum provides better radio-opacity, which enables easy 
Table 2 Published data on device closure of ruptured sinus of Valsalva aneurysm

\begin{tabular}{|c|c|c|c|}
\hline Author & Year of publication & No. of cases & Device used \\
\hline Cullen et $\mathrm{al}^{7}$ & 1994 & 1 & Rashkind umbrella \\
\hline Rao et $\mathrm{al}^{12}$ & 2003 & 1 & Gianturco coil \\
\hline Arora et $\mathrm{al}^{6}$ & 2004 & 8 & ADO (5), ASO (1), and Rashkind umbrella (2) \\
\hline Chang et al $^{13}$ & 2006 & 4 & ADO (3) and Gianturco coil (1) \\
\hline Zhao et $\mathrm{a}^{14}$ & 2008 & 10 & ADO \\
\hline Sen et al $^{15}$ & 2009 & 8 & Heart PDA \\
\hline Szkutnik et al ${ }^{16}$ & 2009 & 6 & $\begin{array}{l}\text { ADO (5) } \\
\text { ASO (1) }\end{array}$ \\
\hline Kerkar et $\mathrm{al}^{9}$ & 2010 & 20 & ADO \\
\hline Guan et $\mathrm{al}^{10}$ & 2013 & 10 & PDA (8) and VSD (2) \\
\hline Radhakrishnan et al ${ }^{11}$ & 2013 & 13 & ADO \\
\hline
\end{tabular}

Abbreviations: ADO, Amplatz Duct occluder; ASO, Amplatz septal occluder; PDA, patent ductus arteriosus occluder; VSD, ventricular septal occluder.

positioning of the device in the defect. However, our decision was based mainly on its user-friendly price. To the best of our knowledge, this is the largest series with this device in RSOVA.

Residual shunt, development of AR or worsening of AR, IE, coronary ostial encroachment, and failure to deploy are important complications of device closure in RSOVA described in the literature so far. We had residual shunt at discharge in one patient which disappeared at 1 month follow-up. It is important to evaluate for possible hemolysis in small residual shunts. We did not find any new AR or worsening of AR or IE in our patients. We had failure of
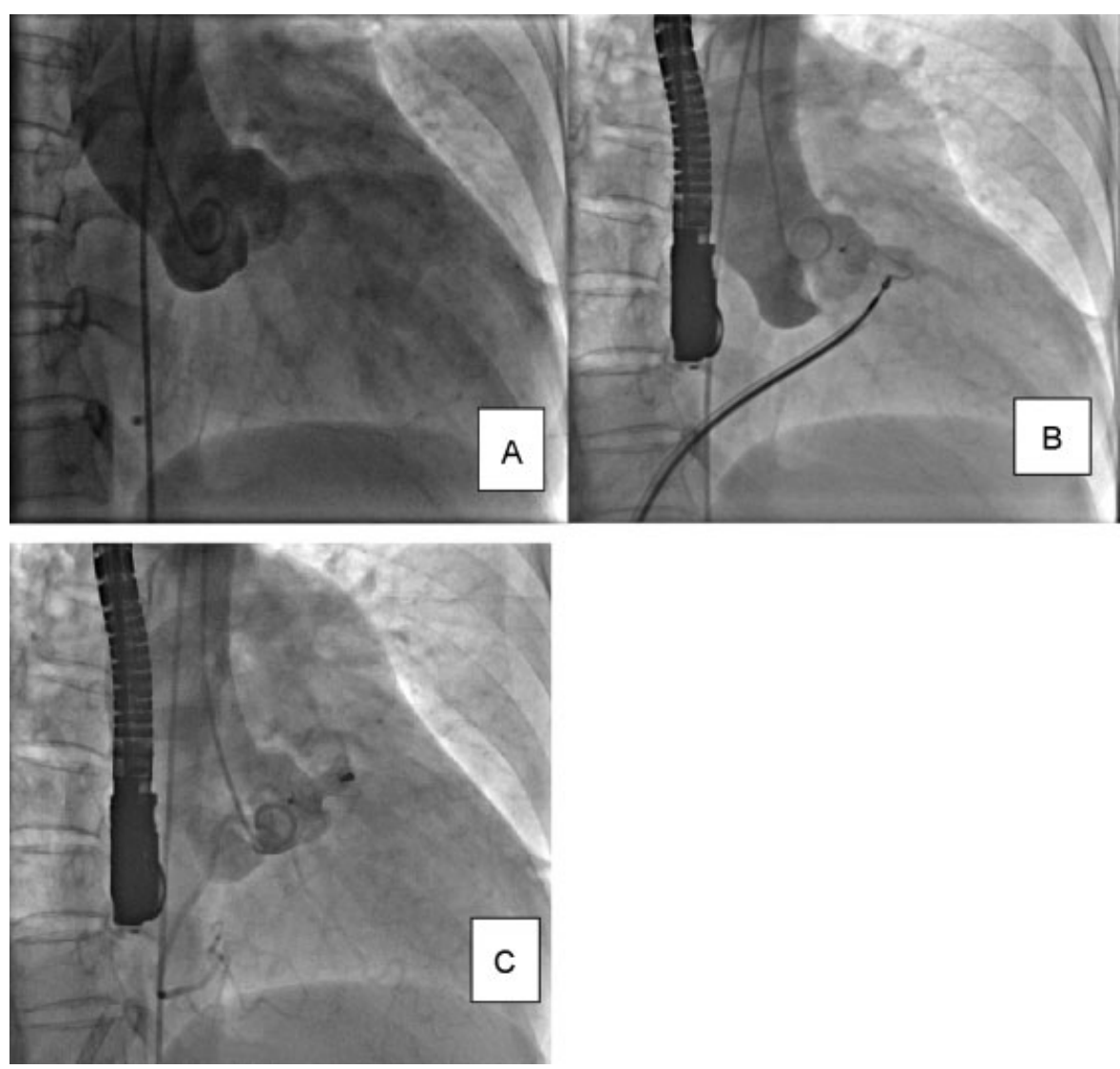

Fig. 1 A: Aortic root angiogram in RAO view: RSOVA to RVOT; B: PDA device positioned under TEE and fluoroscopic guidance; C: Device released, PDA device occluding the defect. PDA, patent ductus arteriosus occluder; RAO, right anterior oblique; RSOVA, ruptured sinus of Valsalva aneurysm; RVOT, right ventricular outflow tract; TEE, transesophageal echocardiography. 

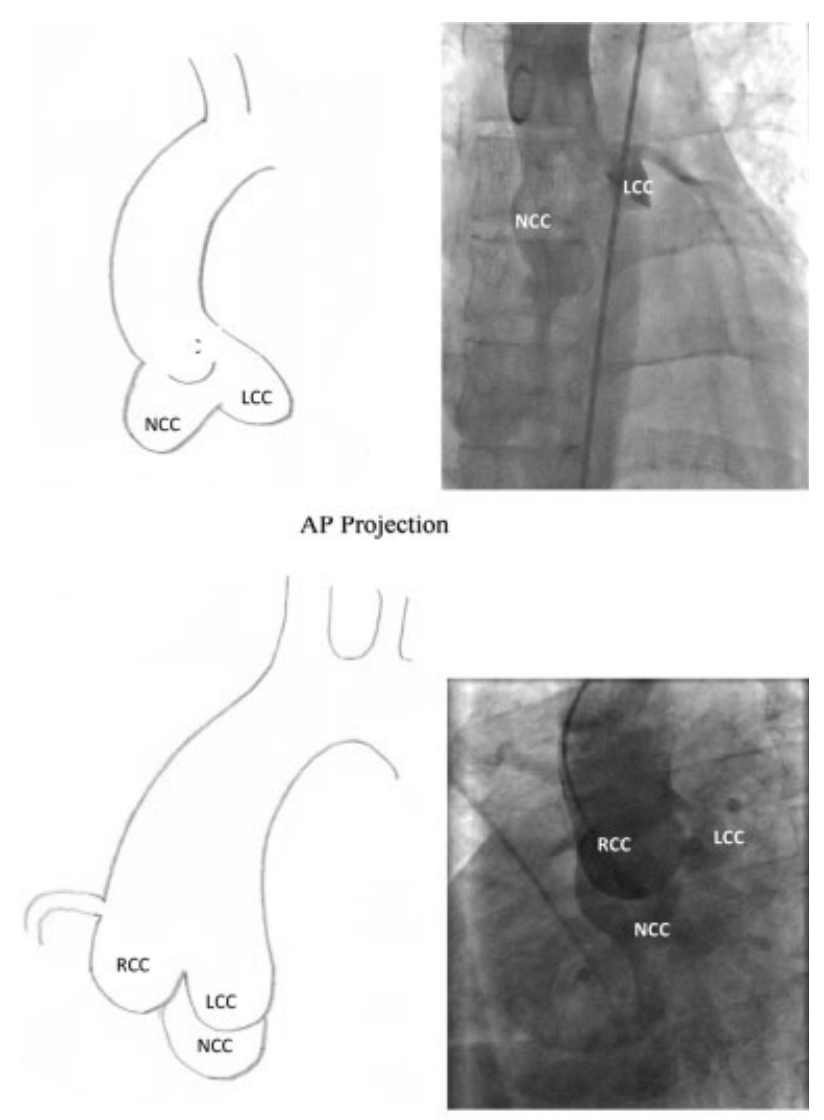

LAO Projection
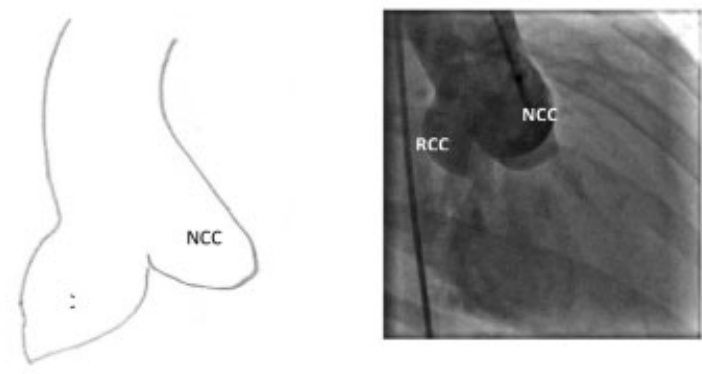

RAO Projection

Fig. 2 Aortogram and schematic representation of aortic cusps in aortic root angiogram in AP, LAO, and RAO projections. AP, anteroposterior; LAO, left anterior oblique; RAO, right anterior oblique.

deployment in one case, after which we restricted percutaneous closure to RSOVA measuring $<12 \mathrm{~mm}$. We did not encounter any coronary ostial encroachment. We checked all results with the TEE as well as the concluding aortic root angiogram. Guan ${ }^{10}$ et al reported one patient developing myocardial infarction which was managed medically. We had one patient with healed IE before device implant, who is stable after 46 months of follow-up. We did not opt for device closure in the presence of VSD, but Guan et al ${ }^{10}$ have reported RSOVA closure in two patients with small VSD, and the VSD was left untreated. In-hospital mortality has been reported by Radhakrishnan et $\mathrm{al}^{11}$ in one patient during the early learning curve.

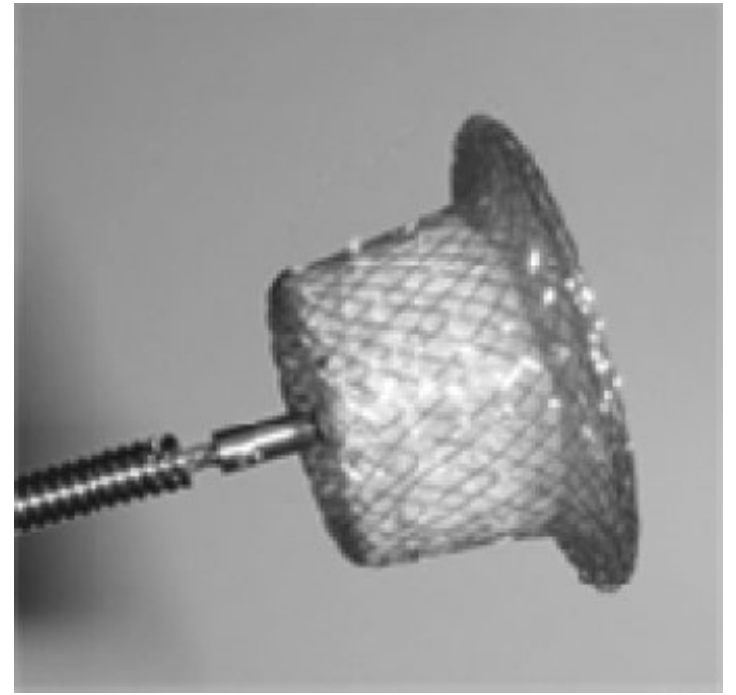

Fig. 3 Cocoon duct occluder (Source: Vascular Innovations, Thailand).

\section{Conclusion}

Percutaneous closure of RSOVA appears to be feasible and safe with good long-term outcomes. Careful selection of cases increases the success rate of the procedure. However, still a longerterm follow-up is needed. The results appear to be at par with closure of other left-to-right shunts in experienced hands.

\section{Summary}

Percutaneous closure of RSOVA is evolving. Relative paucity of cases remains the major limitation, apart from the difficulty in closing defects $>12 \mathrm{~mm}$ with currently available devices. However, complications reported in the literature due to percutaneous closure are scanty, and with the evident good long-term outcome, percutaneous closure may be regarded as a safe alternative to surgery in expert hands.

\section{References}

1 Kirklin JW, Barratt-Boyes BG. Congenital sinus of Valsalva aneurysm and aortic left ventricular tunnel. In: Kirklin JW, BarrattBoyes BG, eds. Cardiac Surgery. 3rd ed. New York: ChurchillLivingstone; 2003:911-927

2 Edwards JE, Burchell HB. The pathological anatomy of deficiencies between the aortic root and the heart, including aortic sinus aneurysms. Thorax 1957;12(2):125-139

3 Fishbein MC, Obma R, Roberts WC. Unruptured sinus of Valsalva aneurysm. Am J Cardiol 1975;35(6):918-922

4 Sakakibara S, Konno S. Congenital aneurysm of the sinus of Valsalva. Anatomy and classification. Am Heart J 1962;63:405-424

5 Sakakibara S, Konno S. Congenital aneurysms of sinus of Valsalva. A clinical study. Am Heart J 1962;63:708-719

6 Arora R, Trehan V, Rangasetty UM, Mukhopadhyay S, Thakur AK, Kalra GS. Transcatheter closure of ruptured sinus of Valsalva aneurysm. J Interv Cardiol 2004;17(1):53-58

7 Cullen S, Somerville J, Redington A. Transcatheter closure of a ruptured aneurysm of the sinus of Valsalva. Br Heart J 1994;71(5): 479-480 
104 RSOV Intervention Sinha et al.

8 Amplatz K, Moller JH. Radiology of Congenital Heart Disease. Mosby Yearbook, St Louis 1993 (2nd ed.), Vol I, Chapter 24, 395406.

9 Kerkar PG, Lanjewar CP, Mishra N, Nyayadhish P, Mammen I. Transcatheter closure of ruptured sinus of Valsalva aneurysm using the Amplatzer duct occluder: immediate results and mid-term follow-up. Eur Heart J 2010;31(23): 2881-2887

10 Guan L, Zhou D, Zhang F, et al. Percutaneous device closure of ruptured sinus of Valsalva aneurysm: a preliminary experience. J Invasive Cardiol 2013;25(10):492-496

11 Radhakrishnan S. Awasthy Neeraj. Transcatheter device closure of ruptured sinus of Valsalva: not addressing the pathology, does it make a difference? TCT-680. J Am Coll Cardiol 2013;62(18):208 (poster abstracts TCT-680 in TCT 2013)
12 Rao PS, Bromberg BI, Jureidini SB, Fiore AC. Transcatheter occlusion of ruptured sinus of Valsalva aneurysm: innovative use of available technology. Catheter Cardiovasc Interv 2003;58(1):130-134

13 Chang CW, Chiu SN, Wu ET, Tsai SK, Wu MH, Wang JK. Transcatheter closure of a ruptured sinus of Valsalva aneurysm. Circ J 2006;70(8):1043-1047

14 Zhao SH, Yan CW, Zhu XY, et al. Transcatheter occlusion of the ruptured sinus of Valsalva aneurysm with an Amplatzer duct occluder. Int J Cardiol 2008;129(1):81-85

15 Sen S, Chattopadhyay A, Ray M, Bandyopadhyay B. Transcatheter device closure of ruptured sinus of Valsalva: immediate results and short term follow up. Ann Pediatr Cardiol 2009;2(1):79-82

16 Szkutnik M, Kusa J, Glowacki J, Fiszer R, Bialkowski J. Transcatheter closure of ruptured sinus of Valsalva aneurysms with an Amplatzer occluder. Rev Esp Cardiol 2009;62(11):1317-1321 